\title{
Factors associated with married women's support of male circumcision for HIV prevention in Uganda: a population based cross-sectional study
}

\author{
Komi Mati ${ }^{1 *}$, Korede K. Adegoke ${ }^{1}$ and Hamisu M. Salihu²
}

\begin{abstract}
Background: Despite the protective effect of male circumcision (MC) against HIV in men, the acceptance of voluntary MC in priority countries for MC scale-up such as Uganda remains limited. This study examined the role of women's sociodemographic characteristics, knowledge of HIV and sexual bargaining power as determinants of women's support of male circumcision (MC).

Methods: Data from the Uganda AIDS Indicator Survey, 2011 were analyzed $(n=4,874)$. Bivariate and multivariate logistic regression analyses with random intercept were conducted to identify factors that influence women's support of MC.

Results: Overall, $67.0 \%(n=3,276)$ of the women in our sample were in support of MC but only $28.0 \%$ had circumcised partners. Women who had the knowledge that circumcision reduces HIV risk were about 6 times as likely to support MC than women who lacked that knowledge [AOR (adjusted odds ratio) $=5.85,95 \% \mathrm{Cl}$ (confidence interval) $=4.83-7.10]$.

The two indicators of women's sexual bargaining power (i.e., ability to negotiate condom use and ability to refuse sex) were also positively associated with support of MC. Several sociodemographic factors particularly wealth index were also positively associated with women's support of MC.
\end{abstract}

Conclusions: The findings in this study will potentially inform intervention strategies to enhance uptake of male circumcision as a strategy to reduce HIV transmission in Uganda.

Keywords: Medical male circumcision, HIV, Women, Sexual bargaining power

\section{Background}

There is a growing appeal from the World Health Organization (WHO), the UN Joint Program on HIV/ AIDS (UNAIDS) and the President's Emergency Plan for AIDS Relief (PEPFAR) for quick scale-up of medical male circumcision (MMC) in areas of high HIV prevalence in sub-Saharan Africa [1-3]. The interest of these organizations in MMC follows findings from several studies, which include three randomized control trials that demonstrated a protective effect of MMC against HIV in men [4-6]. Furthermore, a recent

\footnotetext{
* Correspondence: matik@health.usf.edu

'Department of Epidemiology and Biostatistics, University of South Florida,

13201 Bruce B. Downs Blvd. MDC 56, Tampa, FL, USA

Full list of author information is available at the end of the article
}

epidemiological and economic modeling of the impact and cost of MMC scale-up shows that MMC may be cost-effective [7]. Despite these potential advantages, the acceptance of voluntary MMC in identified priority countries remains limited. Uganda, one of the countries in East Africa that has been identified as a priority country for MMC scale-up, had only reached $11 \%$ of its goal by the end of 2012 [8]. In order to achieve rapid uptake of MMC through targeted interventions in Uganda, it is important to identify factors associated with support for MMC.

Although men are the main focus of MMC education, the literature shows that women can play a central role in the scale-up of MMC [9-13]. Women's beliefs about MMC and their endorsement of MMC significantly 
influence their male partners' or sons' acceptance of MMC [14, 15]. A recent intervention study found an increase in the likelihood of undergoing MMC among participants in their experimental group and attributed this to increased acceptance of MMC among their female partners [16]. Women play a key role in encouraging men to get circumcised and they may be valuable in strategies for increasing MMC uptake $[9,15,16]$. As a result, it is important to investigate the determinants of support for MMC among females.

Studies suggest that knowledge or belief in the protective effect of circumcision on HIV and STI risk may facilitate MMC acceptability among women [12, 17, 18]. Several sociodemographic factors including educational level and religious affiliation have been linked to support for MMC [12, 18]. Another important factor that is related to women's support for MMC include the possibility of having sex with a circumcised man without a condom due to lack of perceived HIV risk [12, 19, 20]. Interestingly, women who oppose MMC have also cited the fear of having sex without a condom as their main reason [12]. A qualitative study in Papua New Guinea found that women's fears about MMC resulting in sexual risk compensation in terms of a decline of condom use was one of the main reasons they didn't support MMC [20]. According to another study, gender relations might negatively influence women's support of MMC through their reaction to the risk compensation behavior that circumcised men may adopt [19]. Maughan-Brown, and Venkataramani [19] suggest that women may give up a costly bargaining for safe sexual practice if they believe erroneously that circumcision prevents HIV transmission from men to women as it did in the case of women to men. Though, that may be potentially true in the case of unmarried women, we do not expect that women in a stable union will give up bargaining a protective behavior because of knowledge of a potential decrease in HIV transmission risk due to MMC. We instead hypothesize that married women who have sexual bargaining power may support MMC knowing that they can easily convince their sexual partner after circumcision to use condoms. This is attributable to the increased awareness among these women about STI risk factors including the protective role of condom use.

In this study, we aim to investigate the association between several women's characteristics including their sexual bargaining power and their support of male circumcision (MC) in Uganda using nationally representative data.

\section{Methods}

\section{Data and variable definitions}

This study used the dataset from the individual file of the 2011 Uganda AIDS Indicator Survey (UAIS 2011). The UAIS 2011 is a standardized nationally representative, population based cross-sectional survey designed to produce a range of HIV/AIDS indicators. The data has been validated and used to produce an official report [21]. The overall goal of the survey is to provide program managers and policy makers with information to effectively plan, implement and evaluate HIV/AIDS interventions. In this analysis, only women who were currently in stable marital union and whose partners had been surveyed were included. The restriction of the study sample to married and cohabiting women was necessary because only women in a stable union were asked the question regarding women's ability to request condom use or refuse sex. This restriction also allowed for investigating the association between women's support of MC and having circumcised partners. Though 4,900 women met the aforementioned inclusion criteria, our final sample size was 4,874 because 26 women who had never heard about HIV were excluded.

\section{Dependent variables}

The dependent variable used for the analysis was a dichotomous indicator variable derived from the answer given to the following question: "Male circumcision is the procedure where the foreskin is removed from the penis in males. Would you recommend your male relatives/friends who are not circumcised to go for male circumcision?" This support for $\mathrm{MC}$ variable was coded yes or no and used as a proxy for MMC. If the respondent did not know or was unsure, it was coded no.

\section{Key explanatory variables}

Five key independent variables were considered: (a) socioeconomic characteristics. (b) knowledge of the protective effect of circumcision, (c) having a circumcised spouse, (d) being able to request condom use, and (e) being able to refuse sex. The socioeconomic control factors in the analysis included wealth index, education level, ethnicity, age, religion, and place (rural or urban) of residence. The wealth indicators were included in the analysis as an ordinal variable of five wealth quintiles. The quintiles were computed using multiple component analysis which was based on a list of assets usually possessed in urban and rural areas of Uganda. The education variable was also an ordinal variable representing four levels of attainment: no formal education, primary school, secondary school, and tertiary school. Knowledge of the protective effect of circumcision was assessed through the answer to the question: does male circumcision help prevent getting infected with the AIDS virus? The two indicators of safer sex negotiation were derived from the women's answers to two questions: "Can the respondent ask her partner to use a condom?" and "Can the respondent refuse sex?". 


\section{Other predictors variables}

These included the following HIV/AIDS related variables: comprehensive knowledge of HIV/AIDS, negative attitudes toward people living with HIV (PLWHIV), and HIV testing status; these variables were all dichotomized.

\section{Data analyses}

Descriptive statistics using number (n) and percentages (\%) were used to define the characteristics of the study population. Chi-square tests were applied to assess differences in the distribution of the independent variables across the MC support categories. Bivariate and multivariate logistic regression analyses were run to assess the association between women's support of MC and the independent factors presented above. A three-level random intercept specification was used for the multivariate analysis. This specification allowed us to account for the survey's sampling method which is multi-clustered, with villages as the primary sampling unit selected from administrative divisions (district or regions) [22, 23]. The multilevel specification also took into account some unobservable factors at the cluster level as well as the reciprocal influence that people in the same community may have on each other. This approach has been used to model HIV testing status among Nigerian couples using the 2008 Nigeria Demographic and Health Survey (DHS) which was conducted following a sampling frame similar to the data used in this study [24]. We conducted all statistical analyses using STATA 13 and a $p$-value of $\leq 0.05$ was used to denote statistical significance. A brief description of the model used in this study is presented below.

\section{Description of the three levels random intercept model}

Let us denote by $y_{i j k}$ the latent variable representing a woman's support for male circumcision, with $\mathrm{i}, \mathrm{j}, \mathrm{k}$ indexing respectively the woman, her village and her region.

$$
\begin{gathered}
y_{i j k}^{*}=a_{0}+\sum_{p=1}^{P} \beta_{p} x_{p i j k}+u_{j k}+v_{k}+\varepsilon_{i j k} \\
u_{j k} \sim N\left(0, \sigma_{u}^{2}\right) \\
v_{k} \sim N\left(0, \sigma_{v}^{2}\right)
\end{gathered}
$$

The observed response (coded as a dummy variable) is related to the latent variable by:

$$
\begin{aligned}
& y_{i j k}=1 \text { if } y_{i j k}^{*}>0, y_{i j k}=0 \text { otherwise } \\
& P\left(\varepsilon_{i j k}<h\right)=\frac{e^{h}}{1+e^{h}}, E\left(\varepsilon_{i j k}\right)=0, \operatorname{var}\left(\varepsilon_{i j k}\right)=\frac{\pi^{2}}{3}
\end{aligned}
$$

With $\sigma_{v}^{2}, \sigma_{u}^{2}$, and $\frac{\pi^{2}}{3}$ representing respectively the variance between regions, the variance between villages within regions, the variance between women within a village and a region by assumption. The variance between villages is equal to $\sigma_{u}^{2}+\sigma_{v}^{2}$. Two different intra-class correlations for the latent responses $\left(y_{i j k}^{*}\right)$ can also be derived from the model [25]:

Correlation across villages within the same region:

$$
\rho_{\text {region }}=\operatorname{corr}\left(y_{i j k}^{*}, y_{i^{\prime} j^{\prime} k}^{*} \mid x_{i j k,}, x_{i^{\prime} j^{\prime} k}\right)=\frac{\sigma_{v}^{2}}{\sigma_{v}^{2}+\sigma_{u}^{2}+\frac{\pi^{2}}{3}}
$$

Correlation across women within the same village

$$
\rho_{\text {village/region }}=\operatorname{corr}\left(y_{i j k}^{*}, y_{i^{\prime} j k}^{*} \mid x_{i j k}, x_{i^{\prime} k}\right)=\frac{\sigma_{u}^{2}+\sigma_{v}^{2}}{\sigma_{v}^{2}+\sigma_{u}^{2}+\frac{\pi^{2}}{3}}
$$

If $\rho_{\text {village/region }}>\rho_{\text {region }}$, then we can suspect that women who live in the same village have similar attitudes toward male circumcision that differ from those of women who reside in the same region, but in a different village.

\section{Results}

\section{Characteristics of the sample}

Table 1 shows the sociodemographic characteristics of the study sample. Overall, $67.0 \%(n=3,276$ women $)$ of the sample were in support of MC. Most of the participants had at least primary school education (64.1\%), were less than 35 years of age $(65.1 \%)$, predominantly Catholic (42.9\%) and rural residents $(86.8 \%)$. MC supporters were more likely to be of younger age, to have at least secondary level education, of higher wealth index ( $p$-value $<0.0001)$. They were also more likely to be Muslims, urban residents and of Baganda/ Basoga ethnic groups ( $p$-value $<0.0001)$.

In Table 2, we present the HIV/AIDs related characteristics of the sample. About $40.2 \%(n=1961)$ of women believed that circumcision prevents HIV but only $28.0 \%$ of the women had circumcised partners. Women who supported MC were more likely to believe that circumcision prevents HIV and were more likely to possess sexual bargaining power (i.e. refuse sex and negotiate condom use). They were also more likely to have comprehensive knowledge of HIV/AIDS and circumcised partners $(p<0.0001)$.

\section{Factors associated with women's support of male circumcision}

In Table 3, we illustrate the results from the bivariate and the multivariate logistic regression analyses. The likelihood ratio test, which compares a simple logistic specification to that of the three-level random intercept, showed that the latter represents the better fit with the data (chi-square $=$ $460, p$ value $<0.0001$ ). The analysis of the intra-class correlation revealed that the within-region (between villages) difference accounted for $29 \%$ (ICC $=0.29,95 \%$ CI: 0.18, 0.43) of the total variance, while $18 \%$ (ICC $=0.18,95 \%$ CI: 0.08 , 0.37 ) of the total variance stemmed from differences 
Table 1 Socio-demographic Characteristics of Sample, Uganda AIDS Indicator Survey 2011

\begin{tabular}{|c|c|c|c|c|}
\hline \multirow{3}{*}{ Variables } & \multicolumn{4}{|c|}{ Support Male Circumcision } \\
\hline & Total $(4,874)$ & Yes $(3,276)$ & No $(1,598)$ & $P$-values \\
\hline & $n(\%)$ & $n(\%)$ & $n(\%)$ & \\
\hline \multicolumn{5}{|l|}{ Education } \\
\hline No education & $892(18.3)$ & $431(48.3)$ & $461(51.7)$ & \multirow[t]{4}{*}{$<0.0001$} \\
\hline Primary & $3125(64.1)$ & $2130(68.2)$ & $995(31.8)$ & \\
\hline Secondary & 710 (14.6) & $592(83.4)$ & $118(16.6)$ & \\
\hline Tertiary & $147(3.02)$ & $123(83.7)$ & $24(16.3)$ & \\
\hline \multicolumn{5}{|l|}{ Age groups } \\
\hline $15-24$ & $1356(27.8)$ & $956(70.5)$ & $400(29.5)$ & \multirow[t]{4}{*}{$<0.0001$} \\
\hline $25-34$ & $1819(37.3)$ & $1267(69.7)$ & $552(30.4)$ & \\
\hline $35-44$ & $1195(24.5)$ & 769 (64.4) & $426(35.7)$ & \\
\hline 45 and over & $504(10.3)$ & $284(56.4)$ & $220(43.7)$ & \\
\hline \multicolumn{4}{|l|}{ Wealth Index } & \multirow[t]{6}{*}{$<0.0001$} \\
\hline Poorest & $1032(21.2)$ & $511(49.5)$ & $521(50.5)$ & \\
\hline Poorer & $1113(22.8)$ & $674(60.6)$ & 439 (39.4) & \\
\hline Middle & $985(20.2)$ & $682(69.2)$ & $303(30.8)$ & \\
\hline Richer & $878(18.0)$ & $660(75.2)$ & $218(24.8)$ & \\
\hline Richest & $866(17.8)$ & $749(86.5)$ & $117(13.5)$ & \\
\hline \multicolumn{5}{|l|}{ Religion } \\
\hline Catholic & $2093(42.9)$ & $1206(57.6)$ & $887(42.4)$ & \multirow[t]{5}{*}{$<0.0001$} \\
\hline Protestant & $1572(32.3)$ & $1069(68.0)$ & $503(32.0)$ & \\
\hline Pentecostal & $396(8.1)$ & $263(66.4)$ & $133(33.6)$ & \\
\hline Muslim & $604(12.4)$ & $575(95.2)$ & $29(4.8)$ & \\
\hline Other religion & 209 (4.3) & $163(78.0)$ & $46(22.0)$ & \\
\hline \multicolumn{5}{|l|}{ Place of Residence } \\
\hline Urban & $643(13.2)$ & $542(84.3)$ & $101(15.7)$ & \multirow[t]{2}{*}{$<0.0001$} \\
\hline Rural & $4231(86.8)$ & 2734 (64.6) & $1497(35.4)$ & \\
\hline \multicolumn{5}{|c|}{ Access to Health facility } \\
\hline Yes & $1788(36.7)$ & $1262(70.6)$ & $526(29.4)$ & \multirow[t]{2}{*}{$<0.0001$} \\
\hline No & $3086(63.3)$ & $2014(65.3)$ & $1072(34.7)$ & \\
\hline \multicolumn{5}{|l|}{ Ethnic groups } \\
\hline Baganda & $596(12.23)$ & $523(87.75)$ & $73(12.25)$ & \multirow[t]{6}{*}{$<0.0001$} \\
\hline Banyankole & $402(8.25)$ & $274(68.16)$ & $128(31.84)$ & \\
\hline Basoga & $481(9.87)$ & $464(96.47)$ & $17(3.53)$ & \\
\hline Bakiga & $266(5.46)$ & $155(58.27)$ & $111(41.73)$ & \\
\hline Itesa & $449(9.21)$ & $243(54.12)$ & $206(45.88)$ & \\
\hline Other & $2680(54.99)$ & $1,617(60.34)$ & 1,063 (39.66) & \\
\hline
\end{tabular}

between regions. This result suggests that the attitudes of women from the same village were correlated.

Younger, wealthier, more educated, and Muslim women were more likely to support MC. Religion was one the greatest predictor of $\mathrm{MC}$ as Muslims were about four times as likely to support MC compared to Catholics (AOR = 3.81, 95 \% CI 2.32-6.28). With regards to ethnicity, women of Itesa ethnic group were about $50 \%$ less likely than those of Baganda ethnic group to support MC (AOR $=0.52,95 \%$ CI 0.307-0.898). Women who knew that MC reduces the risk of HIV transmission were more likely to support $\mathrm{MC}$ (AOR $=5.85,95$ \% CI 4.80-7.1). Comprehensive knowledge of HIV/AIDS was positively associated with women's support of $\mathrm{MC}(\mathrm{AOR}=1.30,95 \% \mathrm{CI} 1.00-1.58)$. Women who 
Table 2 HIV/AIDS related Characteristics of Sample, Uganda AIDS Indicator Survey 2011

\begin{tabular}{|c|c|c|c|c|}
\hline \multirow{3}{*}{ Variables } & \multicolumn{4}{|c|}{ Support Male Circumcision } \\
\hline & Total $(4,874)$ & Yes $(3,276)$ & No $(1,598)$ & $P$-values \\
\hline & $n(\%)$ & $n(\%)$ & $n(\%)$ & \\
\hline \multicolumn{5}{|c|}{ Circumcision prevents HIV } \\
\hline Yes & $1961(40.2)$ & $1738(88.6)$ & $223(11.4)$ & \multirow[t]{2}{*}{$<0.0001$} \\
\hline No & $2913(59.8)$ & $1538(52.8)$ & $1375(47.2)$ & \\
\hline \multicolumn{5}{|c|}{ Circumcised partner } \\
\hline Yes & $1366(28.0)$ & $1216(89.0)$ & $150(11.0)$ & \multirow[t]{2}{*}{$<0.0001$} \\
\hline No & $3508(72.0)$ & $2060(58.7)$ & $1448(41.3)$ & \\
\hline \multicolumn{5}{|c|}{ Request condom } \\
\hline Yes & $3030(62.2)$ & $2305(76.1)$ & $725(23.9)$ & \multirow[t]{2}{*}{$<0.0001$} \\
\hline No & $1844(37.8)$ & $971(52.7)$ & $873(47.3)$ & \\
\hline \multicolumn{5}{|c|}{ Refuse intercourse } \\
\hline Yes & $3762(77.2)$ & $2706(71.9)$ & $1056(28.1)$ & \multirow[t]{2}{*}{$<0.0001$} \\
\hline No & $1112(22.8)$ & $570(51.3)$ & $542(48.7)$ & \\
\hline \multicolumn{5}{|c|}{ Ever tested for HIV } \\
\hline Yes & $3743(76.8)$ & $2525(67.5)$ & $1218(32.5)$ & \multirow[t]{2}{*}{0.506} \\
\hline No & $1131(23.2)$ & $751(66.4)$ & $380(33.6)$ & \\
\hline \multicolumn{5}{|c|}{ Comprehensive HIV knowledge } \\
\hline Yes & $1546(31.7)$ & $1181(76.4)$ & $365(23.6)$ & \multirow[t]{2}{*}{$<0.0001$} \\
\hline No & $3328(68.3)$ & $2095(62.9)$ & $1233(37.1)$ & \\
\hline \multicolumn{5}{|c|}{ Stigmatize PLHV } \\
\hline Yes & 3807 (78.1) & 2610 (68.6) & 1197 (31.4) & \multirow[t]{2}{*}{0.0002} \\
\hline No & 1067 (21.9) & $666(62.4)$ & 401 (37.6) & \\
\hline
\end{tabular}

had a circumcised partner were 3.3 times as likely to support MC compared to their counterparts whose partners were not circumcised ( $\mathrm{AOR}=3.29,95 \% \mathrm{CI}$ 2.49-4.37). The two indicators of women's sexual bargaining power were positive predictors of support for MC. Women who could negotiate condom use were almost twice as likely to support $\mathrm{MC}(\mathrm{AOR}=1.79,95 \% \mathrm{CI} 1.48-2.16)$, and women who reported having the ability to refuse sex were about $50 \%$ more likely than their counterparts to support $\mathrm{MC}$ (AOR 1.45, 95 \% CI 1.18-1.77).

\section{Discussion}

This study investigated factors that influence women's support of MC in Uganda. The results show that about $67 \%$ of married women supported MC; that is, they were willing to recommend $\mathrm{MC}$ to their male relatives. This is consistent to some extent with findings from previous studies [13, 26]. Although Westerkamp and Baily [13] included all women from diverse countries, irrespective of their marital status, our findings do share a significant overlap in consistency with theirs. Similarly, Mavhu et al.[26] found that $58 \%$ and $60 \%$ of women in their study (which include $67 \%$ of married women) in rural Zimbabwe would respectively like their partners and their sons circumcised if it protected them against HIV. The restriction of the sample used for our analysis to only married women could explain the slightly higher prevalence of MC support in our study. Though we found high level of support for MC only about one-third of married women who supported $\mathrm{MC}$ had circumcised partners. This discordance might be due to the fact that MMC scale-up is a new idea in Uganda [3] and the translation of increase in women's support and recommendation to uptake of circumcision will take a while. Other barriers to circumcision such as lack of knowledge of health unit where circumcision can be performed, cost, disbelief that MC protects against HIV, cultural issues, fear of pain or adverse effect $[18,26,27]$ may also explain this low level of partner's circumcision rate in the presence of high level of women's support. The greatest positive predictors of married women's support of MC in our study were knowledge that MMC can decrease the risk of HIV transmission, having a circumcised male partner, being Muslim and women's sexual bargaining power (measured by ability to request condom use and refuse sexual intercourse). An innovative aspect of this research is our investigation of the role of women's sexual bargaining power in women's support of MC. 
Table 3 Predictors of Married Women's Support of Male Circumcision in Uganda

\begin{tabular}{|c|c|c|}
\hline & Crude OR (95 \% Cl) & AOR $(95 \% \mathrm{Cl})$ \\
\hline Circumcision prevent HIV & $6.97(5.95-8.15)^{* * *}$ & $5.85(4.83-7.1)^{* * *}$ \\
\hline Circumcised male partner & $5.70(4.75-6.84)^{* * *}$ & $3.29(2.49-4.37)^{* * *}$ \\
\hline Request condom use & $2.86(2.53-3.24)^{* * *}$ & $1.79(1.48-2.16)^{* * *}$ \\
\hline Refuse sexual intercourse & $2.44(2.12-2.80)^{* * *}$ & $1.45(1.18-1.77)^{* * *}$ \\
\hline Ever tested for HIV & $1.05(0.91-1.21)$ & $1.11(0.90-1.37)$ \\
\hline Comprehensive HIV & $1.90(1.66-2.18)^{* * *}$ & $1.30(1.08-1.58)^{* *}$ \\
\hline Stigmatize PLHV & $1.31(1.14-1.51)^{* * *}$ & $0.93(0.76-1.14)$ \\
\hline \multicolumn{3}{|l|}{ Education } \\
\hline No education & 1.00 & 1.00 \\
\hline Primary & $2.29(1.97-2.66)^{* * *}$ & $1.46(1.17-1.82)^{* * *}$ \\
\hline Secondary & $5.37(4.23-6.80)^{* * *}$ & $1.41(0.99-2.01)$ \\
\hline Tertiary & $5.48(3.47-8.65)^{* * *}$ & $1.31(0.70-2.46)$ \\
\hline \multicolumn{3}{|l|}{ Age group } \\
\hline $15-24$ & 1.00 & 1.00 \\
\hline $25-34$ & $0.96(0.82-1.12)$ & $1.23(0.99-1.51)$ \\
\hline $35-44$ & $0.76(0.64-0.89)^{* * *}$ & $1.08(0.85-1.37)$ \\
\hline 45 and over & $0.54(0.44-0.67)^{* * *}$ & $0.91(0.67-1.23)$ \\
\hline \multicolumn{3}{|l|}{ Wealth quintiles } \\
\hline Poorest & 1.00 & 1.00 \\
\hline Poorer & $1.57(1.32-1.86)^{* * *}$ & $1.07(0.85-1.36)$ \\
\hline Middle & $2.29(1.91-2.75)^{* * *}$ & $1.07(0.82-1.39)$ \\
\hline Richer & $3.09(2.54-3.75)^{* * *}$ & $1.32(0.99-1.77)$ \\
\hline Richest & $6.53(5.19-8.21)^{* * *}$ & $1.74(1.15-2.62)^{* *}$ \\
\hline \multicolumn{3}{|l|}{ Religion } \\
\hline Catholic & 1.00 & 1.00 \\
\hline Protestant & $1.56(1.36-1.79)^{* * *}$ & $1.07(0.88-1.30)$ \\
\hline Pentecostal & $1.45(1.16-1.82)^{* *}$ & $0.97(0.71-1.32)$ \\
\hline Muslim & $14.58(9.94-21.39)^{* * *}$ & $3.81(2.32-6.28)^{* * *}$ \\
\hline Other religion & $2.61(1.86-3.66)^{* * *}$ & $1.06(0.67-1.66)$ \\
\hline Residence urban/rural & $2.94(2.35-3.67)^{* * * *}$ & $0.99(0.61-1.61)$ \\
\hline Access to health facility & $1.28(1.13-1.45)^{* * *}$ & $1.08(0.89-1.31)$ \\
\hline \multicolumn{3}{|l|}{ Ethnic groups } \\
\hline Baganda & 1.00 & 1.00 \\
\hline Banyankole & $0.30(0.22-0.41)^{* * *}$ & $1.02(0.602-1.744)$ \\
\hline Basoga & $3.81(2.21-6.55)^{* * *}$ & $1.96(0.960-4.017)$ \\
\hline Bakiga & $0.19(0.14-0.28)^{* * *}$ & $0.76(0.435-1.322)$ \\
\hline Itesa & $0.16(0.12-0.22)^{* * *}$ & $0.52(0.307-0.898)^{*}$ \\
\hline Other group & $0.21(0.16-0.27)^{* * * *}$ & $0.77(0.517-1.160)$ \\
\hline \multicolumn{3}{|l|}{ Intraclass correlation } \\
\hline Primary sampling unit & & $0.29(0.18-0.43)^{* * *}$ \\
\hline Region & & $0.18(0.081-0.37)^{* *}$ \\
\hline
\end{tabular}

Significance of $p$-values: ${ }^{* * *} p<0.001,{ }^{* *} p<0.01,{ }^{*} p<0.05$

$O R$ odds ratio, $A O R$ adjusted odds ratio
The positive association between knowledge that $\mathrm{MC}$ reduces risk of HIV infection and women's support of MC corroborates findings from other studies conducted in East African nations $[16,26]$. Our findings also demonstrated that wealthier women are more likely to support MC than their counterparts with lower wealth status. The positive correlation between education and women's support of $\mathrm{MC}$ is consistent with the result of studies conducted in Kenya $[18,26]$. The association between having circumcised partners and married women's support of MC could be explained by the role of other predictors of women's support of MC. These include the benefits of circumcision such as the potential increase of pleasure $[18,28]$ and penile hygiene $[10,29]$. We also observed a positive association between urban residency and women's support of MC in the unadjusted model. This concurs with findings from the KwaZulu-Natal province in South Africa [28]. However, the fact that the association became insignificant in the multivariate model suggests that it is not urban residency per se that facilitates women's support of MC but rather the preponderance of other facilitators in the urban area. These facilitators may include higher wealth level, knowledge and the reduction of some ethnicity barriers.

Religion and ethnicity were also associated with $\mathrm{MC}$ support in this study. Married Muslim women were more likely than Catholics to support MC. This is because Muslims practice male circumcision for religious reasons [30]. However, unlike other public health topics where religious doctrine is against a health practice (such as the Catholicism and the use of modern contraception), there is no religious doctrine that prohibits male circumcision [31]. With regards to ethnicity, women of Itesa ethnic group were less likely than those of Baganda ethnic group to support MC. Report from the 2011 Demographic and Health Survey showed that men of Itesa ethnic group had the lowest prevalence of circumcision (7 \%) in Uganda [32]. Further research is required to understand why Itesa ethnic group women do not support $\mathrm{MC}$ and the reason for low circumcision rate among their male population. Targeted intervention is required to increase $\mathrm{MC}$ support among sub-populations such as Catholics, other Christians, and the Itesa ethnic group.

Based on the findings from the random effects test, our study also revealed that significant variations exist in women's support of MC across regions in Uganda. That the intra-class correlation remained significant after controlling for ethnicity and religions signifies that other unobservable influential factors may exist and remain unaccounted for. Further research is required to explore the reasons for the differences in women's support of MC across regions in Uganda.

Our study has some limitations. First, the variable male circumcision (MC) was used as a proxy for medical male circumcision (MMC). This could have resulted in 
an overestimation of support for MMC and the measures of association for MMC support. Second, due to the structure of the dataset, our sample was restricted to only married women. Therefore, our findings must be interpreted with caution as factors associated with $\mathrm{MC}$ support among unmarried younger women in uncommitted relationships may be different than those for married women. For instance, the effect of sexual bargaining power on MC support may be different for this population and so interventions to improve their sexual bargaining power may also be unique. Further research is required to explore factors associated with support of MC among this population and whether their support actually influence circumcision uptake.

The strengths of this study include the large sample size and generalizability of study findings to married women in Uganda due to the use of a nationally representative dataset. The outcome, support for MC was based on a very sensitive query that correctly classifies individuals who support and do not support MMC: 'Would you recommend your male relatives/friends who are not circumcised to go for male circumcision'. This is because if an individual recommends $\mathrm{MC}$, it is highly probable they will support MS. The converse is also true. To our knowledge, this is the first to demonstrate a relationship between women's sexual bargaining power and support for MC.

\section{Conclusion}

This study has identified several factors that may be targeted in order to increase uptake of MMC among Ugandan men. The importance of promoting educational campaigns to increase women's knowledge of the benefits of MMC is key. Tailored interventions toward women irrespective of their age, particularly poor women and those of religious groups that are less likely to support MMC is recommended. It is also essential to develop programs and policies that can equip married women with the skills and/or power to negotiate safer sex. Overall, this study underscores the necessity to give prime importance to the role of women and the need to include them in interventions that aim at achieving MMC scale-up in Uganda.

\section{Abbreviations}

AIDS, Acquired immune deficiency syndrome; Cl, Confidence intervals; HIV, human immunodeficiency virus; MMC, medical male circumcision, MC male circumcision; PEPFAR, President's Emergency Plan for AIDS Relief; UNAIDS, United Nation Joint Program on HIV/AIDS; WHO, World Health Organization

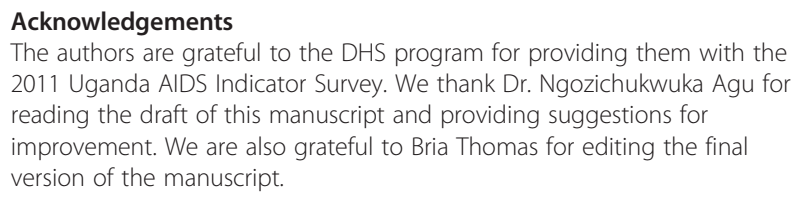

Funding

Not applicable.

\section{Availability of data and materials}

The dataset supporting the conclusions of this article is available at the DHS program, http://dhsprogram.com/data/dataset/Uganda_StandardAIS_2011.cfm?flag. The data are not publicly available but can be accessible by request and with permission of the DHS program. Restrictions apply to the availability of these data, which were used under permission granted to the first author.

\section{Authors' contributions}

KM conceptualized the study, analyzed the data and contributed to drafting of the manuscript, KA contributed to the data analysis plan, literature review and write-up of the manuscript and HS contributed to writing the manuscript. All authors read and approved the final manuscript.

\section{Authors' information}

KM is a candidate for a Master of Public Health Degree in Biostatistics in the Department of Epidemiology and Biostatistics, University of South Florida, Tampa, Florida, and adjunct faculty at the State College of Florida BradentonSarasota, Bradenton, Florida; KA is a Ph.D. candidate in the Department of Epidemiology and Biostatistics, University of South Florida, Tampa, Florida; HS is a Professor and Vice Chair (Research) in the Department of Family and Community Health, Baylor College of Medicine, Houston, Texas.

\section{Competing interests}

The authors declare that they have no competing interests.

\section{Consent for publication}

Not applicable.

\section{Ethics approval and consent to participate}

The survey and procedures were approved by the Science and Ethics Committee of the Uganda Virus Research, Institute, ICF Macro's Institutional Review Board and a review committee at the Centers for Disease Control and Prevention (CDC) in Atlanta. The dataset used in this study is not publicly available. Access to the dataset and study approval was received from the Demographic and Health Surveys program.

\section{Author details}

${ }^{1}$ Department of Epidemiology and Biostatistics, University of South Florida, 13201 Bruce B. Downs Blvd. MDC 56, Tampa, FL, USA. ²Department of Family and Community Health, Baylor College of Medicine, Houston, TX, USA.

Received: 11 March 2016 Accepted: 27 July 2016

Published online: 02 August 2016

\section{References}

1. Reed JB, Njeuhmeli E, Thomas AG, Bacon MC, Bailey R, Cherutich P, Curran K, Dickson K, Farley T, Hankins C, et al. Voluntary medical male circumcision: an HIV prevention priority for PEPFAR. J Acquir Immune Defic Syndr. 2012;60(3):S88-95.

2. WHO/UNAIDS. Joint strategic action framework to accelerate the scale up of voluntary medical male circumcision fro HIV prevention in Eastern and Southern Africa. Geneva, Switzerland: Joint United Nations Programme on HIV/AIDS. Geneva: Joint United Nations Programme on HIV/AIDS; 2011.

3. WHO/UNAIDS. New data on male circumcision and HIV PREVENTION: policy and programme implications. WHO/UNAIDS Technical Consultation on Male Circumcision and HIV Prevention: Research Implications for Policy and Programming. Conclusions and Recommendations. Montreux: World Health Organization; 2007.

4. Auvert B, Taljaard D, Lagarde E, Sobngwi-Tambekou J, Sitta R, Puren A. Randomized, controlled intervention trial of male circumcision for reduction of HIV infection risk: the ANRS 1265 Trial. PLoS Med. 2005;2(11), e298.

5. Bailey RC, Moses S, Parker CB, Agot K, Maclean I, Krieger JN, Williams CFM, Campbell RT, Ndinya-Achola JO. Male circumcision for HIV prevention in young men in Kisumu, Kenya: a randomised controlled trial. Lancet. 2007;369(9562):643-56.

6. Gray RH, Kigozi G, Serwadda D, Makumbi F, Watya S, Nalugoda F, Kiwanuka N, Moulton LH, Chaudhary MA, Chen MZ, et al. Male circumcision for HIV prevention in men in Rakai, Uganda: a randomised trial. Lancet. 2007;369(9562):657-66. 
7. Njeuhmeli E, Forsythe S, Reed J, Opuni M, Bollinger L, Heard N, Castor D, Stover J, Farley T, Menon V, et al. Voluntary medical male circumcision: modeling the impact and cost of expanding male circumcision for HIV prevention in eastern and southern Africa. PLoS Med. 2011;8(11), e1001132.

8. WHO. Progress in scaling up voluntary medical male circumcision for HIV prevention in East and Southern Africa January_-December 2012. Africa Republic of Congo: World Health Organization; 2013.

9. Lanham M, L'Engle KL, Loolpapit M, Oguma IO. Women's roles in voluntary medical male circumcision in Nyanza Province, Kenya. PLoS ONE. 2012;7(9), e44825.

10. Ngalande R, Levy J, Kapondo CN, Bailey R. Acceptability of male circumcision for prevention of HIV infection in Malawi. AIDS Behav. 2006;10(4):377-85

11. Shacham E, Godlonton S, Thornton RL. Perceptions of male circumcision among married couples in rural Malawi. J Int Assoc Provid AIDS Care. 2014;13(5):443-9

12. Westercamp M, Agot KE, Ndinya-Achola J, Bailey RC. Circumcision preference among women and uncircumcised men prior to scale-up of male circumcision for HIV prevention in Kisumu, Kenya. AIDS Care. 2012;24(2):157-66

13. Westercamp N, Bailey RC. Acceptability of male circumcision for prevention of HIV/AIDS in Sub-Saharan Africa: a review. AIDS Behav. 2007;11(3):341-55.

14. Bailey RC, Muga R, Poulussen R, Abicht H. The acceptability of male circumcision to reduce HIV infections in Nyanza Province, Kenya. AIDS Care. 2002;14(1):27-40.

15. Jones D, Cook R, Arheart K, Redding CA, Zulu R, Castro J, Weiss SM. Acceptability, knowledge, beliefs, and partners as determinants of Zambian men's readiness to undergo medical male circumcision. AIDS Behav. 2014;18(2):278-84.

16. Cook R, Jones D, Redding CA, Zulu R, Chitalu N, Weiss SM. Female partner acceptance as a predictor of men's readiness to undergo voluntary medical male circumcision in Zambia: the spear and shield project. AIDS Behav. 2015;1:11.

17. Friedland BA, Apicella L, Schenk KD, Sheehy M, Hewett PC. How informed are clients who consent? A mixed-method evaluation of comprehension among clients of male circumcision services in Zambia and Swaziland. AIDS Behav. 2013;17(6):2269-82.

18. Mattson CL, Bailey RC, Muga R, Poulussen R, Onyango T. Acceptability of male circumcision and predictors of circumcision preference among men and women in Nyanza Province, Kenya. AIDS Care. 2005;17(2):182-94.

19. Maughan-Brown B, Venkataramani AS. Learning that circumcision is protective against HIV: risk compensation among men and women in Cape Town, South Africa. PLoS ONE. 2012;7(7), e40753.

20. Kelly A, Kupul M, Aeno H, Shih P, Naketrumb R, Neo J, Fitzgerald L, Kaldor JM, Siba PM, Vallely A. Why women object to male circumcision to prevent HIV in a moderate-prevalence setting. Qual Health Res. 2013;23(2):180-93.

21. Uganda Ministry of Health, ICF International Inc. Uganda AIDS Indicator Survey 2011. Kampala: Uganda Ministry of Health, ICF International Inc; 2012.

22. De Leeuw J, Meijer E. Handbook of multilevel analysis. New York: Springer; 2008.

23. Hedeker D. Multilevel models for ordinal and nominal variables. In: Leeuw J, Meijer E, editors. Handbook of multilevel analysis. New York: Springer; 2008. p. 237-74

24. Lépine A, Terris-Prestholt F, Vickerman P. Determinants of HIV testing among Nigerian couples: a multilevel modelling approach. Health Policy Plan. 2015;30(5):579-92.

25. Siddiqui $\mathrm{O}$, Hedeker D, Flay BR, Hu FB. Intraclass correlation estimates in a school-based smoking prevention study outcome and mediating variables, by sex and ethnicity. Am J Epidemiol. 1996;144(4):425-33.

26. Mavhu W, Buzdugan R, Langhaug LF, Hatzold K, Benedikt C, Sherman J, Laver SM, Mundida O, Woelk G, Cowan FM. Prevalence and factors associated with knowledge of and willingness for male circumcision in rural Zimbabwe. Tropical Med Int Health. 2011;16(5):589-97.

27. Mugwanya KK, Baeten JM, Nakku-Joloba E, Katabira E, Celum C, Tisch D, Whalen C. Knowledge and Attitudes About Male Circumcision for HIV-1 Prevention among Heterosexual HIV-1 Serodiscordant Partnerships in Kampala, Uganda. AIDS Behav. 2010;14(5):1190-7.

28. Scott BE, Weiss HA, Viljoen J. The acceptability of male circumcision as an HIV intervention among a rural Zulu population, Kwazulu-Natal, South Africa. AIDS Care. 2005;17(3):304-13.

29. Halperin DT, Fritz K, McFarland W, Woelk G. Acceptability of adult male circumcision for sexually transmitted disease and HIV prevention in Zimbabwe. Sex Transm Dis. 2005;32(4):238-9.
30. Weiss HA, Halperin D, Bailey RC, Hayes RJ, Schmid G, Hankins CA. Male circumcision for HIV prevention: from evidence to action? AIDS (London, England). 2008;22(5):567-74.

31. Tram KH, Bertrand JT. Correlates of male circumcision in Eastern and Southern African countries: establishing a baseline prior to VMMC Scale-up. PLoS ONE. 2014;9:e100775.

32. Uganda Ministry of Health, ICF International Inc. Uganda Demographic and Health Survey 2011. Kampala: Uganda Ministry of Health, ICF International Inc: 2012.

\section{Submit your next manuscript to BioMed Central and we will help you at every step:}

- We accept pre-submission inquiries

- Our selector tool helps you to find the most relevant journal

- We provide round the clock customer support

- Convenient online submission

- Thorough peer review

- Inclusion in PubMed and all major indexing services

- Maximum visibility for your research

Submit your manuscript at www.biomedcentral.com/submit

) Biomed Central 